\title{
Synergetic protective effect of remote ischemic preconditioning and prolyl 4-hydroxylase inhibition in ischemic cardiac injury
}

\author{
JUESHENG YANG ${ }^{1}$, JIAJUN XU $^{2}$, LEI TAO $^{3}$, SHIYONG WANG ${ }^{4}$, HAIYAN XIANG $^{1}$ and YANHUA TANG ${ }^{1}$ \\ ${ }^{1}$ Department of Cardiovascular Surgery, The Second Affiliated Hospital of Nanchang University, Nanchang, Jiangxi 330036; \\ ${ }^{2}$ Department of Cardiothoracic Surgery, Jiujiang No. 1 People's Hospital, Jiujiang, Jiangxi 332000; ${ }^{3}$ Department of Bone and \\ Soft Tissue Oncology, The Affiliated Hospital of Jiangxi University of Traditional Chinese Medicine, Nanchang, Jiangxi 330006; \\ ${ }^{4}$ Department of Clinical Medicine, Medical College of Nanchang University, Nanchang, Jiangxi 330036, P.R. China
}

Received March 24, 2020; Accepted June 21, 2021

DOI: $10.3892 / \mathrm{mmr} .2022 .12596$

\begin{abstract}
It has been reported that hypoxia-inducible factor $1 \alpha($ HIF-1 $\alpha)$ serves a key role in the protective effect of remote ischemic preconditioning (RIP) in ischemia/reperfusion (I/R)-induced cardiac injury. Moreover, inhibition of prolyl 4-hydroxylase (PHD), an enzyme responsible for HIF-1 $\alpha$ degradation, prevents I/R-induced cardiac injury. However, whether their protective effects are synergetic remains to be elucidated. The present study aimed to investigate the protective effect of RIP, PHD inhibition using dimethyloxalylglycine (DMOG) and their combination on I/R-induced cardiac injury. Rabbits were randomly divided into seven groups: i) Sham; ii) I/R; iii) lung RIP + I/R; iv) thigh RIP + I/R; v) DMOG + I/R; vi) DMOG + lung RIP + I/R; and vii) $\mathrm{DMOG}+$ thigh $\mathrm{RIP}+\mathrm{I} / \mathrm{R}$. I/R models were established via $30 \mathrm{~min}$ left coronary artery occlusion and $3 \mathrm{~h}$ reperfusion. For lung/thigh RIP, rabbits received left pulmonary artery (or left limb) ischemia for $25 \mathrm{~min}$ and followed by release for $5 \mathrm{~min}$. Some rabbits were administered $20 \mathrm{mg} / \mathrm{kg}$ DMOG. The results demonstrated that both lung/thigh RIP and DMOG significantly decreased myocardial infarct size, creatine kinase activity and myocardial apoptosis in I/R rabbits. Furthermore, the combination of RIP and PHD inhibition exerted synergetic protective effects on these aforementioned changes. The mechanistic study indicated that both treatments increased mRNA and protein expression levels of HIF-1 $\alpha$ and its downstream regulators, including vascular endothelial growth factor (VEGF), AKT and endothelial nitric oxide synthase (eNOS). In conclusion, the present study demonstrated that RIP and PHD inhibition exerted synergetic protective effects
\end{abstract}

Correspondence to: Dr Yanhua Tang, Department of Cardiovascular Surgery, The Second Affiliated Hospital of Nanchang University, 566 Xuefu Avenue, Nanchang, Jiangxi 330036, P.R. China

E-mail: tyh6565@163.com

Key words: remote ischemic preconditioning, prolyl 4-hydroxylase, hypoxia-inducible factor- $1 \alpha$, ischemia/reperfusion, cardiac injury on cardiac injury via activation of HIF-1 $\alpha$ and the downstream VEGF/AKT-eNOS signaling pathway.

\section{Introduction}

Myocardial infarction (MI) is the leading cause of mortality among cases of coronary heart disease (1). Although long-term survival following MI has improved over the past three decades, $20 \%$ of patients with MI die within 1 year of the event, with more than half of these deaths occurring within 30 days of MI (2). In clinical practice, various treatments, such as thrombolytic and emergent intervention therapy and coronary artery bypass grafting, have been used to improve timely restoration of the blood supply (3). These treatments effectively decrease damage and death of ischemic myocardial tissue. However, the successful restoration of cardiac blood flow also leads to ischemia/reperfusion injury (IRI), which causes metabolic dysfunction of cardiac muscle and cardiac disorganization (4). These changes ultimately result in secondary damage, as well as arrhythmia and infarct expansion (4). Therefore, is it important to develop a novel therapeutic strategy to protect against IRI.

Previous studies have reported that activation of hypoxia-inducible factor $1 \alpha(\mathrm{HIF}-1 \alpha)$ serves a key role in the therapy strategy of IRI $(5,6)$. For example, it has been shown that ischemic preconditioning of the circumflex coronary artery decreases infarct size following transient, non-lethal prolonged occlusion of the same vessel (5). Przyklenk et al (6) reported that remote ischemic preconditioning (RIP) decreases infarct size following prolonged left anterior descending coronary artery occlusion, and another study revealed that RIP prevents I/R-induced endothelial dysfunction and decreases the extent of myocardial infarction (7). Moreover, a mechanistic study observed that HIF-1 $\alpha$ serves a critical role in the protective effect of RIP (8). It has also been shown that inhibition of HIF-1 $\alpha$ degradation is promising in the treatment of IRI (9-11). During hypoxia, HIF- $1 \alpha$ is hydroxylated, resulting in its ubiquitination and subsequent proteasomal degradation (9). A family of $\mathrm{Fe}^{+2}$ and 2-oxoglutarate-dependent dioxygenases, termed prolyl-4 hydroxylase domain (PHD) 1-3 proteins, are responsible for the hydroxylation of HIF-1 $\alpha$ (10). PHDs can be inhibited by 
dimethyloxalylglycine (DMOG) (12). However, it remains unknown whether RIP and direct PHD inhibition possess synergetic protective effects.

It has been reported that AKT/endothelial nitric oxide synthase (eNOS) and vascular endothelial growth factor (VEGF) serve a key role in the protective signaling pathway in IR (13-15). For example, Wang et al (13) revealed that the herbal drug Tongxinluo protects against pressure overload-induced heart failure in mice via activation of the AKT/eNOS axis. Qiao et al (14) found that transient acidosis during early reperfusion attenuates myocardium IRI via the AKT/eNOS signaling pathway. In addition, VEGF serves an important role in the protective effect in IRI. For example, apigenin protects the brain against IRI via VEGF (15). Another study demonstrated that prolonged cold ischemia in renal graft causes liver pyroptosis and injury at least partially through increased histone release, VEGF improves liver function by suppressing histone-induced hepatocyte pyroptosis via VEGF receptor 2 (16). Furthermore, VEGF may be a downstream regulator of the AKT/eNOS signaling pathway; Kang et al (17) observed that cornin induces angiogenesis via the AKT/eNOS/VEGF signaling pathway.

HIF-1 $\alpha$ regulates the expression of downstream proteins involved in glucose metabolism and angiogenesis, such as VEGF and erythropoietin, to facilitate ischemic adaptation (18). Therefore, the present study evaluated whether RIP and DMOG exert synergetic protective effects in I/R-induced cardiac damage and investigated the potential role of HIF- $1 \alpha$ and the downstream VEGF and AKT/eNOS signaling pathways.

\section{Materials and methods}

Rabbits. All experiments were performed according to the Institutional Guidelines for the Care and Use of Laboratory Animals in Research and were approved by the Committee of the Affiliated Hospital of The Second Affiliated Hospital of Nanchang University.

In total, 40 male rabbits (age, 5-6 months; weight, 2.5-3.0 kg) were purchased from Nanchang Longping Rabbit Co., Ltd. and raised in The Second Affiliated Hospital of Nanchang University. The rabbits were housed at a constant room temperature $\left(23 \pm 2^{\circ} \mathrm{C}\right)$ and relative humidity $(50 \pm 10 \%)$ with free access to food and water and a fixed $12 \mathrm{~h}$ light/dark cycle. The animals were ventilated with a small animal ventilator (Shanghai Alcott Biotech Co., Ltd.) at a rate of 60 breaths/min, inspiratory/expiratory ratio of $1: 3$ and tidal volume of $50 \mathrm{ml}$.

Remote pre-conditioning, DMOG and I/R treatment. Male rabbits were randomly allocated into seven groups: i) Sham ( $\mathrm{n}=6$ ); ii) $\mathrm{I} / \mathrm{R}(\mathrm{n}=8)$; iii) lung (L-)RIP + I/R ( $\mathrm{n}=7)$; iv) thigh (T-) $\mathrm{RIP}+\mathrm{I} / \mathrm{R}(\mathrm{n}=7)$; v) DMOG (D) + I/R (n=7); vi) $\mathrm{D}+\mathrm{L}-\mathrm{RIP}+\mathrm{I} / \mathrm{R}$ $(n=7)$; and vii) $D+T-R I P+I / R(n=7)$. For establishment of the $\mathrm{I} / \mathrm{R}$ model, animals were anesthetized with an ear intravenous (i.v.) injection of $3 \%$ pentobarbital sodium $(30 \mathrm{mg} / \mathrm{kg}$ body weight; supplemented as required) and deep anesthetization was confirmed by loss of the pedal withdrawal reflex. The chest was opened via thoracotomy through the fourth or fifth intercostal space and the heart was exposed (19). A 5-0 prolene was placed around the left main coronary artery (LCA) to create a reversible snare. Prior to LCA occlusion (LCAO), animals were anti-coagulated using $150 \mathrm{U} / \mathrm{kg}$ i.v. sodium heparin (Sigma-Aldrich; Merck KGaA) received i.v. lidocaine (4 mg/kg; Sigma-Aldrich; Merck KGaA) to attenuate arrhythmia. All rabbits underwent a total of $30 \mathrm{~min} \mathrm{LCAO}$, followed by $180 \mathrm{~min}$ reperfusion. The femoral and pulmonary artery were carefully exposed and encircled with a bulldog clamp to form a reversible snare for artery occlusion. Rabbits in the sham group underwent the same thoracotomy procedure but without ligation of the coronary artery.

L/T-RIP was performed as follows: Rabbits were treated with left pulmonary artery (or left limb) ischemia for $25 \mathrm{~min}$, followed by release for $5 \mathrm{~min}$. A total of $20 \mathrm{mg} / \mathrm{kg}$ DMOG (Sigma-Aldrich; Merck KGaA) was administered intraperitoneally $24 \mathrm{~h}$ before cardiac IRI as described previously (20). At the end of the experiment, rabbits were euthanized with an overdose of pentobarbital sodium (3\%; $100 \mathrm{mg} / \mathrm{kg}$ body weight; ear i.v. injection).

Immunohistochemistry and immunofluorescence. Immunohistochemistry and immunofluorescence staining were performed as previously described (21). Hearts were removed and fixed in $4 \%$ paraformaldehyde for $30 \mathrm{~min}$ at $4{ }^{\circ} \mathrm{C}$. Then, tissues were embedded in paraffin and cut into $5-\mu \mathrm{m}$ sections. For hematoxylin and eosin staining, slides were stained with $0.5 \%$ hematoxylin for $10 \mathrm{~min}$ to stain the nuclei and stained with $1 \%$ eosin for $3 \mathrm{~min}$ at room temperature. For immunofluorescence, slices blocked with $1 \%$ non-fat milk for $2 \mathrm{~h}$ at room temperature. The slides were incubated with rabbit anti-caspase-3 primary antibody (1:100; cat. no. ab44976; Abcam) overnight at $4^{\circ} \mathrm{C}$, then with Alexa fluor 555-coupled anti-rabbit secondary antibody $(4 \mu \mathrm{g} / \mathrm{ml}$; cat. no. A-21429; Thermo Fisher Scientific, Inc.) for $1 \mathrm{~h}$ at room temperature. Images were acquired on a confocal spinning disk microscope (400x magnification; Leica Microsystems GmbH).

Area at risk (AAR). The AAR was determined as described previously (22). After clamping the aorta and re-occlusion of the left anterior descending coronary artery, Evans blue dye was injected at $1 \mathrm{ml} / \mathrm{kg}$ body weight and the ventricles were serially sectioned from the apex to base in $1 \mathrm{~cm}$ slices. AAR was determined using Image J software (Version 1.51K, National Institutes of Health) and myocardial infarct size was expressed as a percentage of AAR.

TUNEL. For apoptosis detection, paraffin-embedded heart sections were stained with a TUNEL kit (Roche Diagnostics). A portion of heart tissue was fixed in $4 \%$ paraformaldehyde solution at $4^{\circ} \mathrm{C}$ for $6 \mathrm{~h}$ and cut into $5 \mu \mathrm{m}$-thick paraffinembedded sections. These samples were deparaffinized in xylene for $5 \mathrm{~min}$ and rehydrated with 100 and $95 \%$ ethanol for $3 \mathrm{~min}$ at room temperature. Slides were then digested with proteinase $\mathrm{K}$ and peroxidase activity was blocked with $3 \% \mathrm{H}_{2} \mathrm{O}_{2}$. Following incubation with PBS/0.2\% Tween-20 at room temperature for $30 \mathrm{~min}$, sections were incubated in TdT Reaction Buffer at $37^{\circ} \mathrm{C}$ for $10 \mathrm{~min}$ and TdT Reaction Mixture at $37^{\circ} \mathrm{C}$ for $1 \mathrm{~h}$. Next, sections were incubated with Streptavidin-horseradish peroxidase for $20 \mathrm{~min}$ at room temperature, washed with PBS/0.2\% Tween-20 and incubated 
with $0.66 \mathrm{mg} / \mathrm{ml}$ diaminobenzidine (DAB) substrate at room temperature for 1-2 min. Sections were counterstained with Gill's hematoxylin $(0.5 \%)$ at room temperature for $30 \mathrm{sec}$. Sections were mounted with anti-fading mounting medium and frozen sections were analyzed with a confocal laser scanning microscope (400x magnification; cat. no. LSM 710; Carl Zeiss $\mathrm{GmbH}$ ). A total of four fields/slide was viewed and the average was calculated.

Creatine kinase (CK) activity. Serum CK activity was measured using a colorimetric assay kit (cat. no. K777; BioVision, Inc.) according to the manufacturer's instruction.

Reverse transcription-quantitative $(R T-q) P C R$. RNA samples were extracted using TRIzol ${ }^{\circledR}$ (Invitrogen; Thermo Fisher Scientific, Inc.) and cDNA was synthesized using a SuperScript ${ }^{\mathrm{TM}}$ III First-Strand Synthesis system (Invitrogen; Thermo Fisher Scientific, Inc.) according to the manufacturer's instruction. PCR primers used for qPCR were as follows: HIF-1 $\alpha$ forward, 5'-ATTTTACCCATCCGTGTGAC-3' and reverse, 5'-CTTCCA GGTGGCAGACTTTA-3'; VEGF forward, 5'-ATCATGCGG ATCAAACCTCA-3' and reverse, 5'-CTCGGCTTGTCACAT TTTTC-3'; AKT forward, 5'-CTCATTCCAGACCCACGAC-3' and reverse, 5'-ACAGCCCGAAGTCCGTTA-3'; eNOS forward, 5'-GAGAACGGAGAGAGTTTTGC-3' and reverse, 5'-CTG TTGAAGCGGATTTTGTA-3'; and $\beta$-actin forward, 5'-GCT GTCCCTGTACGCCTCTGG-3' and reverse, 5'-GCTTCTCCT TGATGTCCCGC-3'. The transcript levels of HIF-1 $\alpha$, AKT and eNOS were measured using an ABI 7900 system with a SYBR Green qRT-PCR kit (both Applied Biosystems; Thermo Fisher Scientific, Inc.) according to the manufacturer's instructions. Thermocycling conditions were as follows: $94^{\circ} \mathrm{C}$ for $10 \mathrm{~min}$; 40 cycles at $94^{\circ} \mathrm{C}$ for $5 \mathrm{sec}, 60^{\circ} \mathrm{C}$ for $15 \mathrm{sec}$ and $72^{\circ} \mathrm{C}$ for $2 \mathrm{~min}$; and final step of $72^{\circ} \mathrm{C}$ for $10 \mathrm{~min}$. The relative expression level was normalized to $\beta$-actin using the $\mathrm{Cq}$ method (23).

Western blotting. Tissues were minced with an electric homogenizer and lysed in RIPA buffer (Beyotime Institute of Biotechnology) with constant agitation for $2 \mathrm{~h}$ at $4^{\circ} \mathrm{C}$. Samples were centrifuged for $20 \mathrm{~min}$ at $15,000 \mathrm{x}$ g at $4^{\circ} \mathrm{C}$ and the supernatant was aspirated into new tubes. The protein concentration was determined using a Bradford assay kit. Protein extracts $(10 \mu \mathrm{g} /$ lane $)$ were fractionated on a Tris- $\mathrm{HCl}$ $5-15 \%$ gradient gel (Bio-Rad Laboratories, Inc.) and were then transferred to PVDF membranes (MilliporeSigma). Following blocking with $5 \%$ non-fat milk for $1 \mathrm{~h}$ at room temperature, membranes were incubated using the following antibodies: Anti-HIF-1 $\alpha$ (1:1,000; cat. no. A11945; ABclonal Biotech Co., Ltd.), anti-phosphorylated (p)-AKT (1:2,000; cat. no. 4060; Cell Signaling Technology, Inc.), anti-AKT (1:1,000; cat. no. 4685; Cell Signaling Technology, Inc.) and anti-eNOS (1:1,000; cat. no. 32027; Cell Signaling Technology, Inc.) at $4^{\circ} \mathrm{C}$ overnight. Then, membranes were incubated with horseradish peroxidase-labeled anti-rabbit (cat. no. AS014; ABclonal Biotech Co., Ltd.) or anti-mouse (both 1:2,000; cat. no. AS003; ABclonal Biotech Co., Ltd.) secondary antibodies for $1 \mathrm{~h}$ at room temperature. Anti- $\beta$-actin (1:5,000; cat. no. AC028; ABclonal Biotech Co., Ltd.) served as loading control. Signals were detected with ECL Detection Reagent (Cytiva). Semi-quantification of western blotting bands was performed using ImageJ software (Version 1.51K; National Institutes of Health).

Statistical analysis. Data are presented as the mean \pm SD of 6-8 independent repeats. All data were compared with one-way ANOVA followed by Tukey's post hoc test using GraphPad Prism 6 (GraphPad Software, Inc.). $\mathrm{P}<0.05$ was considered to indicate a statistically significant difference.

\section{Results}

L/T-RIP and DMOG exert a synergetic protective effect on $I / R$-induced myocardial injury. Firstly, the present study evaluated the effect of L/T-RIP on myocardium morphology and infarct size in I/R-treated rabbits. Myocardial cells were neatly arranged in the Sham group, with clear boundaries and intact nuclei (Fig. 1A). By contrast, myocardial cells in the I/R-treated rabbits were disorderly arranged, with unclear boundaries, myofiber rupture and nuclei disappearance. In the L/T-RIP + D groups, the severity of myocardial injuries was notably improved (Fig. 1A). The myocardium infarct size was significantly increased by 8.75 fold in I/R rabbits compared with Sham rabbits; this increase was significantly inhibited in I/R D + L/T-RIP rabbits (Fig. 1B). Moreover, L/T-RIP and DMOG exerted a synergetic effect on decreasing myocardium infarct size, as indicated by changes in AAR in I/R rabbits (Fig. 1B). Consistently, the plasma CK levels, a biochemical marker of cell injury during reperfusion (24), were significantly increased by 3.15 fold, which was significantly decreased by L/T-RIP or DMOG in I/R rabbits (Fig. 1C). L/T-RIP and DMOG had an additive protective effect on CK levels (Fig. 1C). These data indicated that L/T-RIP and DMOG exerted a synergetic protective effect on I/R-induced cardiac damage.

L/T-RIP and DMOG have a synergetic effect on myocardial apoptosis, as indicated by TUNEL and caspase 3 assay. Myocardial apoptosis in cardiac tissue was identified via TUNEL staining. The number of apoptotic cells was significantly increased in the I/R group compared with the Sham group (Fig. 2A and B). Furthermore, L/T-RIP and DMOG exerted a synergetic protective effect and decreased the number of apoptotic myocardiocytes in I/R rabbits.

The effect of L/T-RIP and DMOG on caspase 3, an apoptosis marker, was evaluated using immunofluorescence staining. Caspase 3 was significantly increased, and L/T-RIP and DMOG showed an additive effect on decreasing caspase 3 expression in $\mathrm{I} / \mathrm{R}$ rabbits (Fig. $3 \mathrm{~A}$ and $\mathrm{B}$ ). These results suggested that L/T-RIP and DMOG exerted an enhanced effect on decreasing myocardial apoptosis in $\mathrm{I} / \mathrm{R}$ rabbits.

L/T-RIP and DMOG have a synergetic effect on activating $H I F-1 \alpha, V E G F$ and AKT/eNOS. Next, the changes in HIF-1 $\alpha$ protein expression levels following different treatments were evaluated. Both the mRNA and protein expression levels of HIF-1 $\alpha$ were significantly increased by I/R; the increase was further enhanced by L/T-RIP and DMOG (Fig. 4A and B). Moreover, L/T RIP and DMOG had synergetic effects on increasing HIF-1 $\alpha$ mRNA and protein expression levels hearts from $\mathrm{I} / \mathrm{R}$ rabbits. These results suggested that the additive 


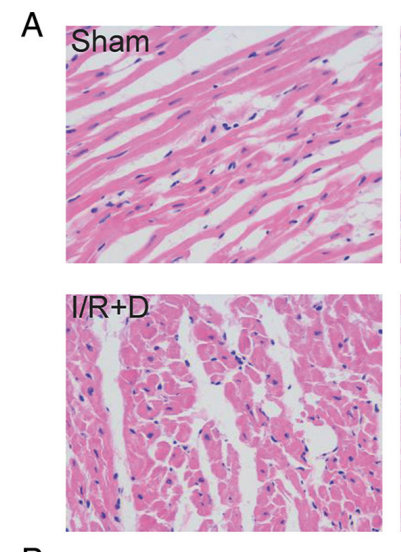

B

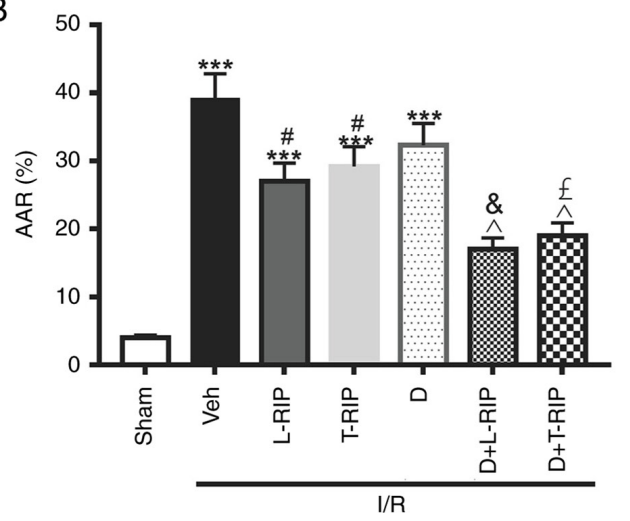

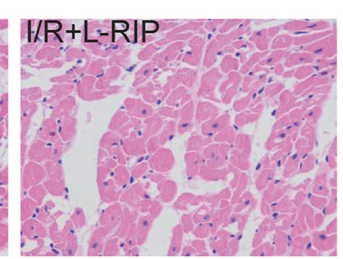
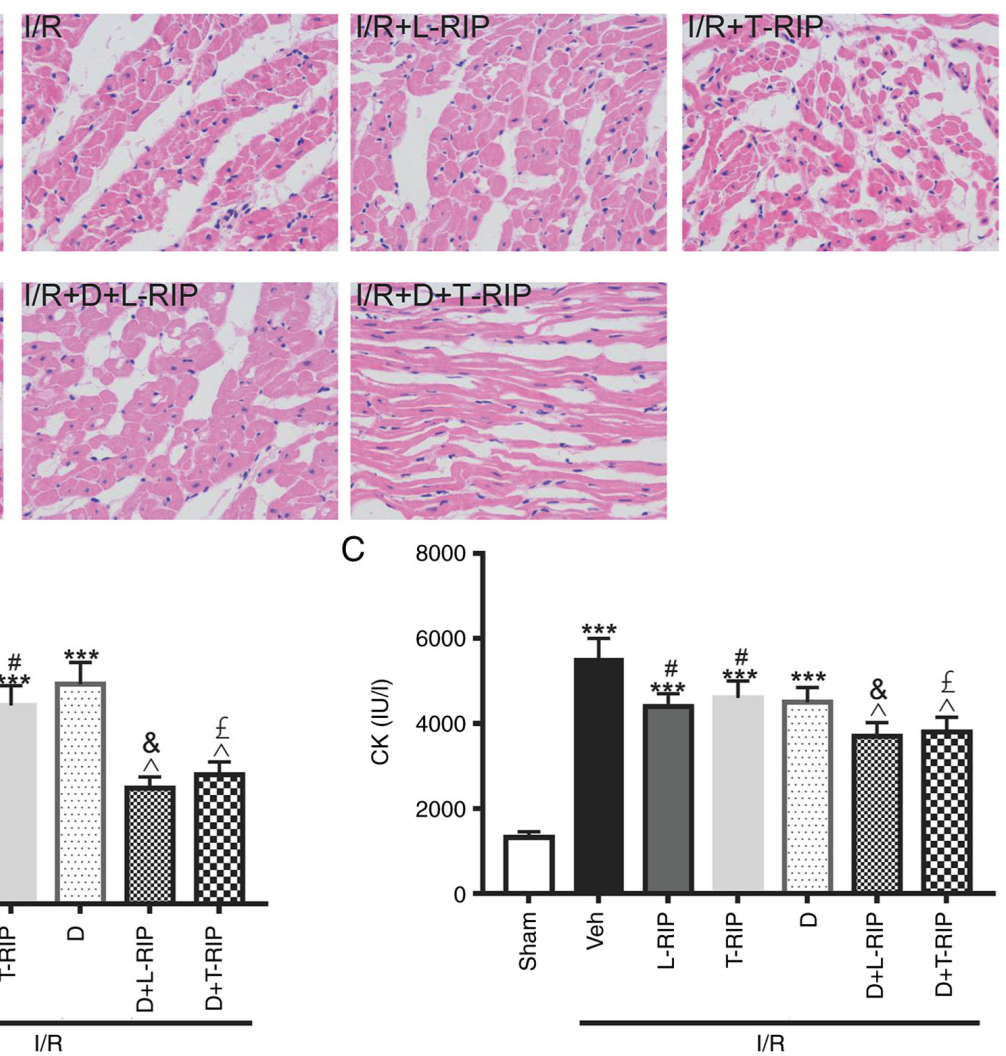

Figure 1. L/T-RIP and D exhibit a synergetic protective effect on cardiac IRI. (A) Representative hematoxylin and eosin staining. Magnification, 400x. Inhibitory effect of L/T RIP and/or D on (B) AAR and (C) CK. ${ }^{* * *} \mathrm{P}<0.001$ vs. Sham; ${ }^{*} \mathrm{P}<0.05$ vs. Veh; ${ }^{\circledR} \mathrm{P}<0.05$ vs. L-TRIP; ${ }^{\mathrm{f}} \mathrm{P}<0.05$ vs. T-RIP; ${ }^{\wedge} \mathrm{P}<0.05$ vs. D. L, lung; T, thigh; RIP, remote ischemic preconditioning; D, dimethyloxalylglycine; IRI, I/R injury; I/R, ischemia/reperfusion; AAR, area at risk; CK, creatine kinase; Veh, Vehicle.
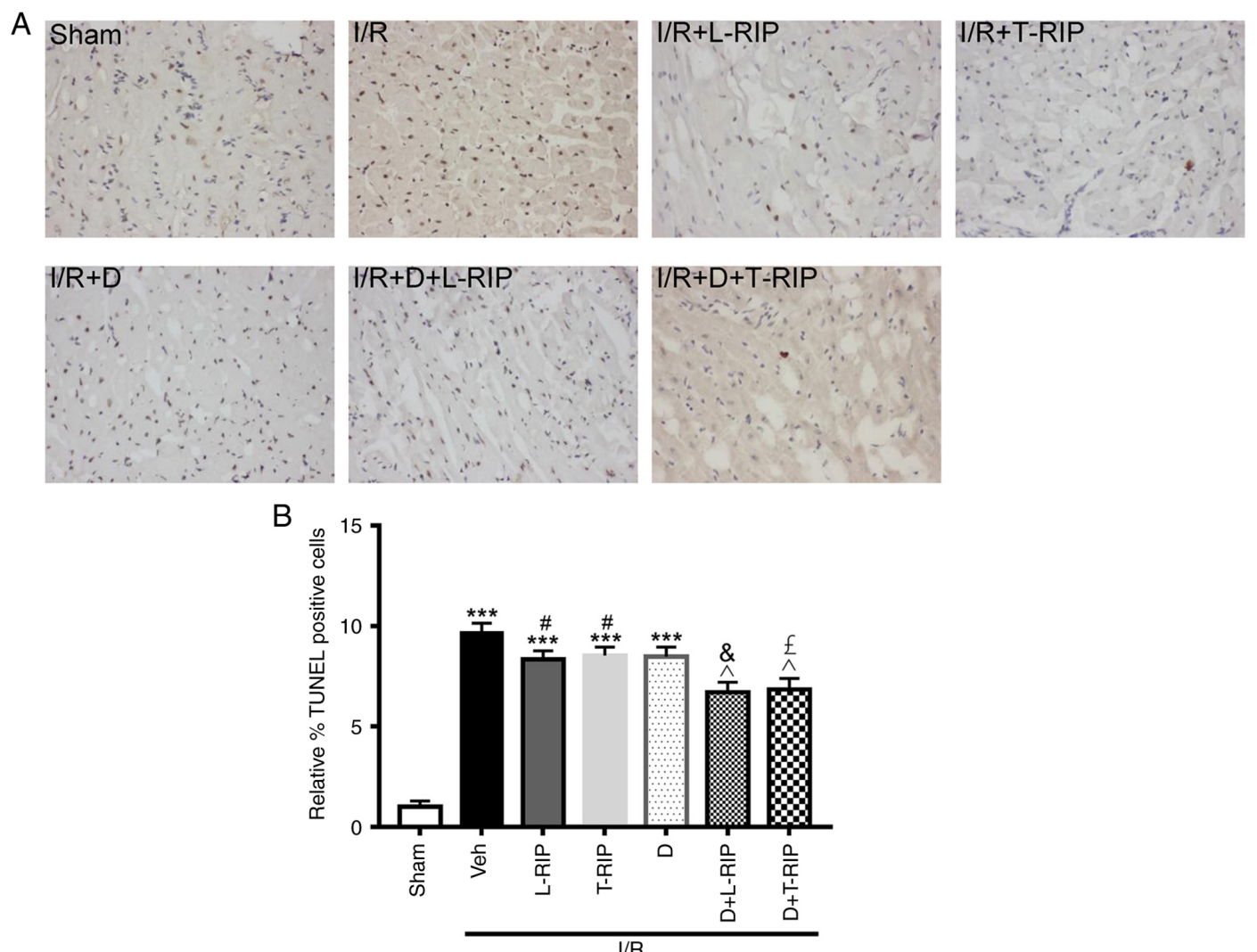

Figure 2. L/T-RIP and D exert a synergetic effect on I/R-induced myocardial apoptosis. (A) Representative TUNEL images. Magnification, 400x. (B) Inhibitory effect of L/T-RIP and/or D on myocardial apoptosis. ${ }^{* * *} \mathrm{P}<0.001$ vs. Sham; ${ }^{*} \mathrm{P}<0.05$ vs. Veh ${ }^{\circledR} \mathrm{P}<0.05$ vs. L-TRIP; ${ }^{\mathrm{f}} \mathrm{P}<0.05$ vs. T-RIP; ${ }^{\wedge} \mathrm{P}<0.05$ vs. D. L, lung; T, thigh; RIP, remote ischemic preconditioning; D, dimethyloxalylglycine; IRI, I/R injury; I/R, ischemia/reperfusion; Veh, Vehicle. 

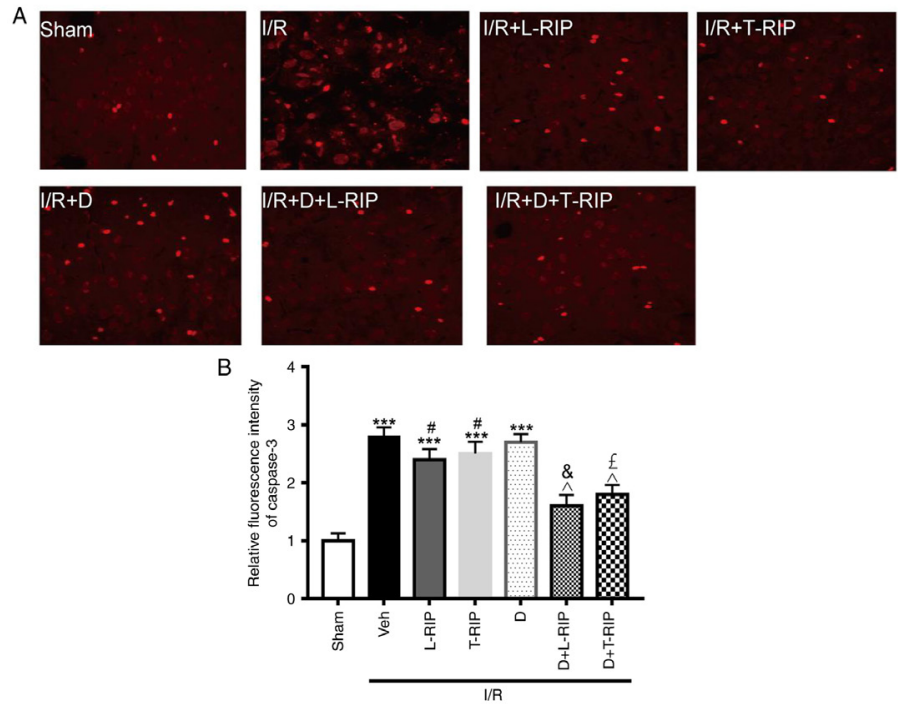

Figure 3.L/T-RIP and D show synergetic effect on I/R-induced caspase 3 expression. (A) Representative fluorescence images. Magnification, 400x. (B) Inhibitory effect of L/T-RIP and/or D on expression of caspase $3 .{ }^{* * *} \mathrm{P}<0.001$ vs. Sham; ${ }^{~} \mathrm{P}<0.05$ vs. Veh; ${ }^{\circledR} \mathrm{P}<0.05$ vs. L-TRIP; ${ }^{\mathrm{A}} \mathrm{P}<0.05$ vs. T-RIP; ${ }^{\wedge} \mathrm{P}<0.05$ vs. D. L, lung; T, thigh; RIP, remote ischemic preconditioning; D, dimethyloxalylglycine; IRI, I/R injury; I/R, ischemia/reperfusion; Veh, Vehicle.

A

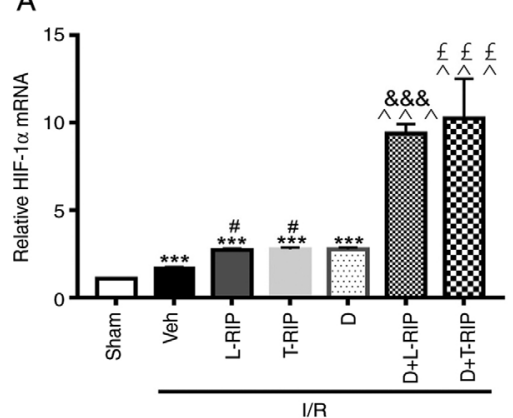

I/R

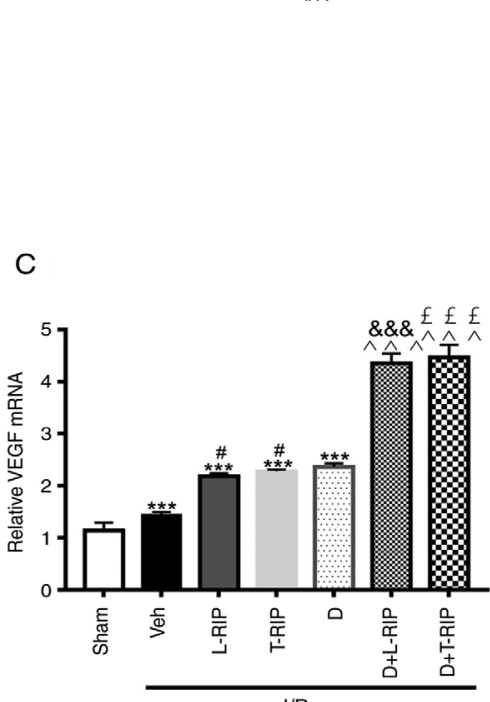

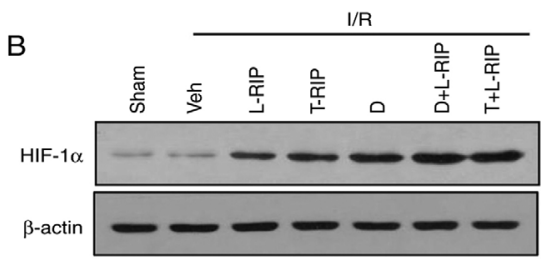

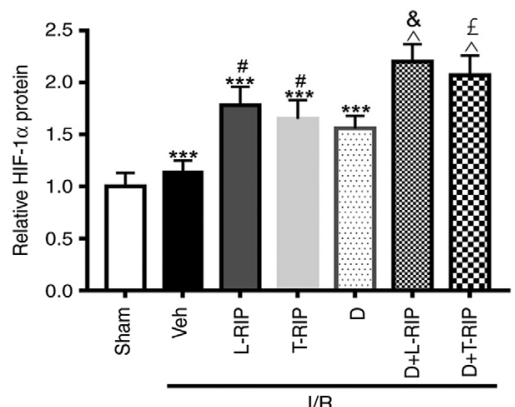

D
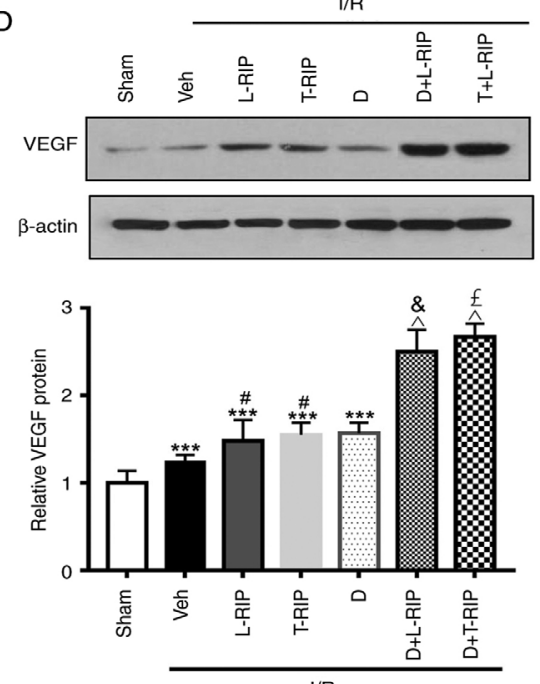

Figure 4. L/T RIP and D show a synergetic effect on I/R-induced expression of HIF-1 $\alpha$ and VEGF. (A) Inhibitory effect of L/T-RIP and/or D on HIF-1 $\alpha$ mRNA levels. (B) Representative western blot images showing the inhibitory effect of L/T-RIP and/or D on HIF-1 $\alpha$ protein levels. (C) Inhibitory effect of L/T-RIP and/or D on VEGF mRNA levels. (D) Representative western blot images showing the inhibitory effect of L/T-RIP and/or D on VEGF protein levels. ${ }^{* * * *} \mathrm{P}<0.001$ vs. Sham; ${ }^{\sharp} \mathrm{P}<0.05$ vs. I $/ \mathrm{R} ;{ }^{\&} \mathrm{P}<0.05$, \&\&\& $\mathrm{P}<0.001$ vs. L-TRIP; ${ }^{\mathfrak{}} \mathrm{P}<0.05,{ }^{\text {fff }} \mathrm{P}<0.001$ vs. T-RIP; ${ }^{\wedge} \mathrm{P}<0.05,{ }^{\wedge \wedge} \mathrm{P}<0.001$ vs. $\mathrm{D}$. L, lung; T, thigh; RIP, remote ischemic preconditioning; D, dimethyloxalylglycine; IRI, I/R injury; I/R, ischemia/reperfusion; Veh, Vehicle. 
A

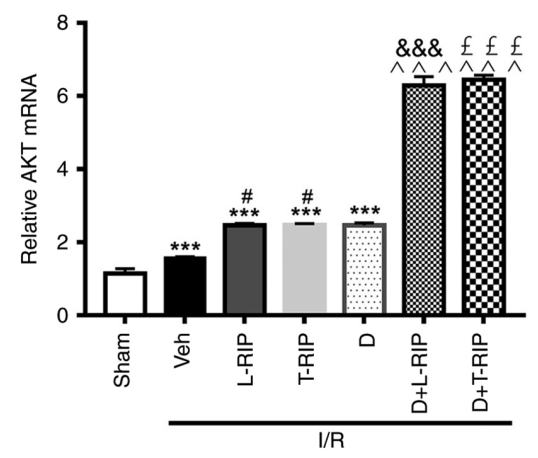

C

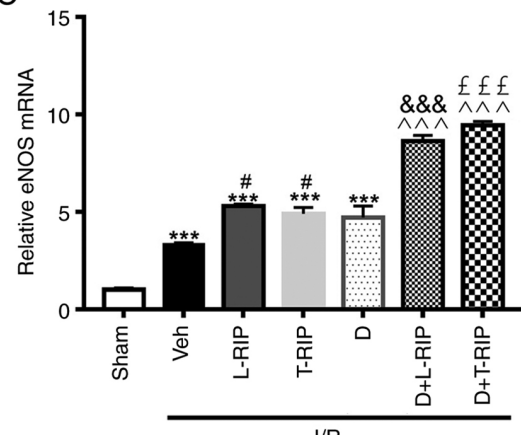

B
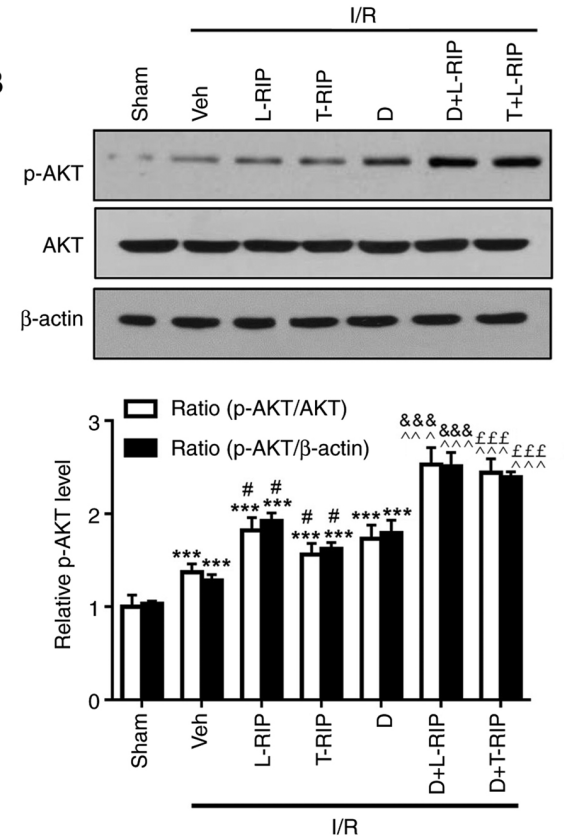

D
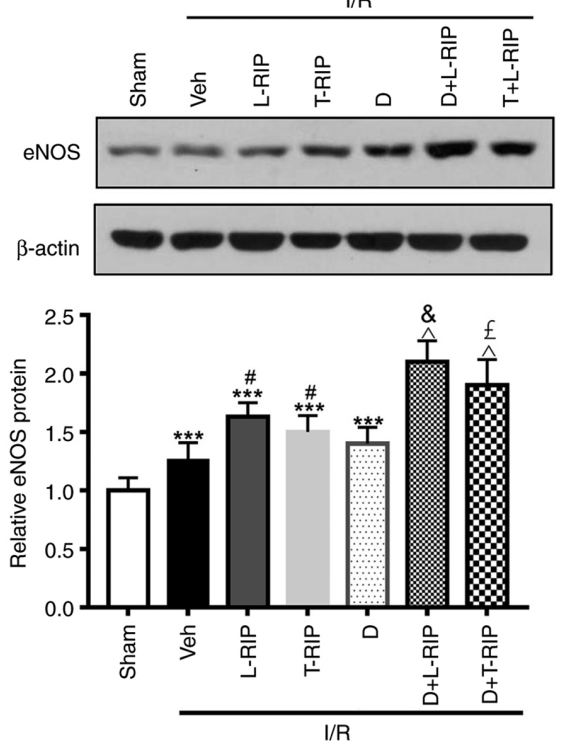

Figure 5. L/T-RIP and D exert a synergetic effect on I/R-induced expression of AKT and eNOS. (A) Inhibitory effect of L/T-RIP and/or D on AKT mRNA levels. (B) Representative western blot images showing the inhibitory effect of L/T-RIP and/or D on AKT protein levels. (C) Inhibitory effect of L/T-RIP and/or D on eNOS mRNA levels. (D) Representative western blot images showing the inhibitory effect of L/T-RIP and D on eNOS protein levels

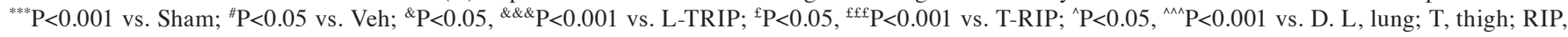
remote ischemic preconditioning; D, dimethyloxalylglycine; IRI, I/R injury; I/R, ischemia/reperfusion; Veh, Vehicle; p, phosphorylated; eNOS, endothelial nitric oxide synthase.

effect of L/T RIP and DMOG may be caused by increasing HIF-1 $\alpha$ expression.

Similarly, both the mRNA and protein expression levels of VEGF, a downstream effector of HIF-1 $\alpha$, were significantly increased by I/R; this upregulation was further enhanced by L/T RIP and DMOG in I/R rabbits. As expected, L/T-RIP and DMOG had a greater effect on increasing VEGF mRNA and protein expression levels.

Previous studies have reported that the AKT/eNOS signaling pathway serves a protective role in experimental IRI $(14,25)$. Here, L/T-RIP and DMOG increased mRNA and protein expression levels of AKT, eNOS and VEGF in I/R rabbits. Notably, L/T-RIP and DMOG exerted an enhanced effect on the mRNA and protein expression levels of AKT in the cardiac tissue of rabbits with I/R (Fig. 5). Furthermore, L/T-RIP and DMOG had a synergetic effect on the mRNA and protein expression levels of eNOS in the cardiac tissue of rabbits with I/R. These results suggested that both L/T-RIP and DMOG exerted a cardiac protective effect via activation of the VEGF and AKT/eNOS signaling pathway.

\section{Discussion}

The present results demonstrated that L/T-RIP and DMOG decreased myocardial infarct size in experimental rabbits. Moreover, L/T-RIP and DMOG exerted a significant 
synergetic protective effect on myocardial injury and cardiac apoptosis. Mechanistically, the two treatments exhibited additive effects on HIF-1 $\alpha$ expression, thereby activating the VEGF and eNOS/HIF-1 $\alpha$ axis. The present study indicated that the combination of RIP and PHD inhibition may be used as a therapy for IRI.

Accumulating evidence has revealed that remote organ preconditioning decreases I/R-induced damage in the heart and kidney (26-28) and that HIF-1 $\alpha$ serves a key role in the protective effect of RIP, which may be mediated by systemic modulation of the inflammatory response to I/R-induced cardiac and lung damage in rats $(20,29)$. Another study observed that RIP protects the heart by increasing expression of HIF-1 $\alpha$ and subsequent activation of IL-10 (30). In line with these studies, the present study demonstrated that $\mathrm{L} / \mathrm{T}$ IP protected I/R-induced cardiac injury by increasing HIF-1 $\alpha$ expression.

Similar to L/T-RIP, the present study identified that DMOG administration decreased cardiac injury and significantly increased HIF-1 $\alpha$ expression. This was consistent with a previous study showing that systemic administration of DMOG in rats increases both the mRNA and protein expression levels of HIF-1 $\alpha$ in blood vessels (31). Furthermore, the present results suggested that RIP and DMOG exerted significant synergetic protective effects and by increasing HIF-1 $\alpha$ expression; their combination may be a favorable strategy for the prevention and treatment of I/R-induced cardiac injury.

Previous studies have revealed that NO is involved in protecting the myocardium following pulmonary IP, which decreases free radical and NO release $(32,33)$. Bai et al (34) reported that Baicalin protects against myocardial IRI via activation of the PI3K/AKT/eNOS pathway. In addition, RIP increases p-ERK expression; inhibition of p-ERK prevents neuronal NOS expression and remote preconditioningmediated neuroprotection (35). In the present study, the mRNA and protein expression levels of AKT and eNOS were significantly increased in the combined L/T-RIP and DMOG groups. These results suggested that the protective role of L/T-RIP and DMOG was exerted via activation of HIF- $1 \alpha$ and the downstream VEGF and AKT/eNOS axis $(20,30)$.

In conclusion, the present study demonstrated that L/T-RIP and DMOG administration immediately before the onset of coronary artery reperfusion decreased myocardial infarct size and that these factors exerted synergetic protective effects on HIF- $1 \alpha$ and the downstream VEGF and AKT-eNOS pathway. The clinical application of L/T-RIP and DMOG in combination may provide a potential strategy for prevention and treatment of I/R-induced cardiac injury.

\section{Acknowledgements}

Not applicable.

\section{Funding}

The present study was supported by the Jiangxi Provincial Natural Science Foundation Project (grant nos. 20171BBG70067 and 20181074) and National Natural Science Foundation of China (grant nos. 81160019 and 81360031).

\section{Availability of data and materials}

The datasets used and/or analyzed during the current study are available from the corresponding author on reasonable request.

\section{Authors' contributions}

JY and YT participated in the design of the study and performed the statistical analysis. JY, JX, SW, HX and LT performed the experiments. JY and YT drafted the manuscript. JY and YT confirm the authenticity of all the raw data. All authors read and approved the final manuscript.

\section{Ethics approval and consent to participate}

All experiments were performed according to the Institutional Guidelines for the Care and Use of Laboratory Animals in Research and were approved by the Committee of the Affiliated Hospital of The Second Affiliated Hospital of Nanchang University.

\section{Patient consent for publication}

Not applicable.

\section{Competing interests}

The authors declare that they have no competing interests.

\section{References}

1. Zhao S, Zhu L, Tinzin L, Huang F, Ma L and Zhou Y: Acute myocardial infarction in a young woman: Unexpected findings of a coronary occlusion. Leg Med (Tokyo) 42: 101662, 2019.

2. Ye Q, Zhang J and Ma L: Predictors of all-cause 1-year mortality in myocardial infarction patients. Medicine (Baltimore) 99: e21288, 2020.

3. Berger JS: Platelet-directed therapies and coronary artery bypass grafting. Am J Cardiol 104 (5 Suppl): 44C-48C, 2009.

4. Zhang S, Wotzkow C, Bongoni AK, Shaw-Boden J, Siegrist M, Taddeo A, Blank F, Hofstetter W and Rieben R: Role of the plasma cascade systems in ischemia/reperfusion injury of bone. Bone 97: 278-286, 2017

5. Murry CE, Jennings RB and Reimer KA: Preconditioning with ischemia: A delay of lethal cell injury in ischemic myocardium. Circulation 74: 1124-1136, 1986.

6. Przyklenk K, Bauer B, Ovize M, Kloner RA and Whittaker P: Regional ischemic 'preconditioning' protects remote virgin myocardium from subsequent sustained coronary occlusion. Circulation 87: 893-899, 1993.

7. Kharbanda RK, Mortensen UM, White PA, Kristiansen SB, Schmidt MR, Hoschtitzky JA, Vogel M, Sorensen K, Redington AN and MacAllister R: Transient limb ischemia induces remote ischemic preconditioning in vivo. Circulation 106: 2881-2883, 2002.

8. Guo JY, Yang T, Sun XG, Zhou NY, Li FS, Long D, Lin T, Li PY and Feng L: Ischemic postconditioning attenuates liver warm ischemia-reperfusion injury through Akt-eNOS-NO-HIF pathway. J Biomed Sci 18: 79, 2011.

9. Hoffman MA, Ohh M, Yang H, Klco JM, Ivan M and Kaelin WG Jr: von Hippel-Lindau protein mutants linked to type $2 \mathrm{C}$ VHL disease preserve the ability to downregulate HIF. Hum Mol Genet 10: 1019-1027, 2001.

10. Bruick RK and McKnight SL: A conserved family of prolyl-4-hydroxylases that modify HIF. Science 294: 1337-1340, 2001.

11. Zheng J, Chen P, Zhong J, Cheng Y, Chen H, He Y and Chen C: HIFl $\alpha$ in myocardial ischemiareperfusion injury (Review). Mol Med Rep 23: 352, 2021. 
12. Hams E, Saunders SP, Cummins EP, O'Connor A, Tambuwala MT, Gallagher WM, Byrne A, Campos-Torres A, Moynagh PM, Jobin C, et al: The hydroxylase inhibitor dimethyloxallyl glycine attenuates endotoxic shock via alternative activation of macrophages and IL-10 production by B1 cells. Shock 36: 295-302, 2011.

13. Wang B, Yang Q, Bai WW, Xing YF, Lu XT, Sun YY and Zhao YX: Tongxinluo protects against pressure overload-induced heart failure in mice involving VEGF/Akt/eNOS pathway activation. PLoS One 9: e98047, 2014.

14. Qiao X, Xu J, Yang QJ, Du Y, Lei S, Liu ZH, Liu X and Liu H: Transient acidosis during early reperfusion attenuates myocardium ischemia reperfusion injury via PI3k-Akt-eNOS signaling pathway. Oxid Med Cell Long 2013: 126083, 2013.

15. Pang Q, Zhao Y, Chen X, Zhao K, Zhai Q and Tu F: Apigenin protects the brain against ischemia/reperfusion injury via caveolin-1/VEGF in vitro and in vivo. Oxid Med Cell Longev 2018: 7017204, 2018

16. Zhao H, Huang H, Alam A, Chen Q, Suen KC, Cui J, Sun Q, Ologunde R, Zhang W, Lian Q and Ma D: VEGF mitigates histone-induced pyroptosis in the remote liver injury associated with renal allograft ischemia-reperfusion injury in rats. Am J Transplant 18: 1890-1903, 2018.

17. Kang Z, Jiang W, Luan H, Zhao F and Zhang S: Cornin induces angiogenesis through PI3K-Akt-eNOS-VEGF signaling pathway. Food Chem Toxicol 58: 340-346, 2013.

18. Zhang Z, Yao L, Yang J, Wang Z and Du G: PI3K/Akt and HIF1 signaling pathway in hypoxiaischemia (Review). Mol Med Rep 18: 3547-3554, 2018.

19. Subramanian VA, McCabe JC and Geller CM: Minimally invasive direct coronary artery bypass grafting: Two-year clinical experience. Ann Thorac Surg 64: 1648-1653, 1997.

20. Ockaili R, Natarajan R, Salloum F, Fisher BJ, Jones D, Fowler AA III and Kukreja RC: HIF-1 activation attenuates postischemic myocardial injury: Role for heme oxygenase-1 in modulating microvascular chemokine generation. Am J Physiol Heart Circ Physiol 289: H542-H548, 2005.

21. He S, Cheng J, Sun L, Wang Y, Wang C, Liu X, Zhang Z, Zhao M, Luo Y, Tian L, et al: HMGB1 released by irradiated tumor cells promotes living tumor cell proliferation via paracrine effect. Cell Death Dis 9: 648, 2018

22. Jazbutyte V, Stumpner J, Redel A, Lorenzen JM, Roewer N, Thum $\mathrm{T}$ and Kehl F: Aromatase inhibition attenuates desflurane-induced preconditioning against acute myocardial infarction in male mouse heart in vivo. PLoS One 7: e42032, 2012.

23. Livak KJ and Schmittgen TD: Analysis of relative gene expression data using real-time quantitative PCR and the 2(-Delta Delta C(T)) method. Methods 25: 402-408, 2001

24. Luo Y, Pan YZ, Zeng C, Li GL, Lei XM, Liu Z and Zhou SF: Altered serum creatine kinase level and cardiac function in ischemia-reperfusion injury during percutaneous coronary intervention. Med Sci Monit 17: CR474-CR479, 2011.
25. Fujimoto H, Ohno M, Ayabe S, Kobayashi H, Ishizaka N, Kimura H, Yoshida KI and Nagai R: Carbon monoxide protects against cardiac ischemia-reperfusion injury in vivo via MAPK and Akt-eNOS pathways. Arterioscler Thromb Vasc Biol 24: 1848-1853, 2004.

26. Billah M, Ridiandries A, Allahwala U, Mudaliar H, Dona A, Hunyor S, Khachigian LM and Bhindi R: Circulating mediators of remote ischemic preconditioning: Search for the missing link between non-lethal ischemia and cardioprotection. Oncotarget 10: 216-244, 2019.

27. Zarbock A and Kellum JA: Remote ischemic preconditioning and protection of the kidney-a novel therapeutic option. Crit Care Med 44: 607-616, 2016.

28. Lim SY and Hausenloy DJ: Remote ischemic conditioning: From bench to bedside. Front Physiol 3: 27, 2012

29. Jin Y, Zhao X, Zhang H, Li Q, Lu G and Zhao X: Modulatory effect of silymarin on pulmonary vascular dysfunction through HIF-1 $\alpha$-iNOS following rat lung ischemia-reperfusion injury. Exp Ther Med 12: 1135-1140, 2016.

30. Cai Z, Luo W, Zhan H and Semenza GL: Hypoxia-inducible factor 1 is required for remote ischemic preconditioning of the heart. Proc Natl Acad Sci USA 110: 17462-17467, 2013.

31. Yuan Q, Bleiziffer O, Boos AM, Sun J, Brandl A, Beier JP, Arkudas A, Schmitz M, Kneser U and Horch RE: PHDs inhibitor DMOG promotes the vascularization process in the AV loop by HIF-1a up-regulation and the preliminary discussion on its kinetics in rat. BMC Biotechnol 14: 112, 2014.

32. Nagasaka Y, Fernandez BO, Steinbicker AU, Spagnolli E, Malhotra R, Bloch DB, Bloch KD, Zapol WM and Feelisch M: Pharmacological preconditioning with inhaled nitric oxide (NO): Organ-specific differences in the lifetime of blood and tissue NO metabolites. Nitric Oxide 80: 52-60, 2018.

33. Totzeck M, Hendgen-Cotta U and Rassaf T: Concepts of hypoxic NO signaling in remote ischemic preconditioning. World J Cardiol 7: 645-651, 2015.

34. Bai J, Wang Q, Qi J, Yu H, Wang C, Wang X, Ren Y and Yang F: Promoting effect of baicalin on nitric oxide production in CMECs via activating the PI3K-AKT-eNOS pathway attenuates myocardial ischemia-reperfusion injury. Phytomedicine 63: $153035,2019$.

35. Liu ZJ, Chen C, Li XR, Ran YY, Xu T, Zhang Y, Geng XK, Zhang Y, Du HS, Leak RK, et al: Remote ischemic preconditioning-mediated neuroprotection against stroke is associated with significant alterations in peripheral immune responses. CNS Neurosci Ther 22: 43-52, 2016.

This work is licensed under a Creative Commons Attribution-NonCommercial-NoDerivatives 4.0 International (CC BY-NC-ND 4.0) License. 